\title{
História dos movimentos sociais na fronteira sul: oportunização política, mobilização e enquadramento interpretativo na luta pela terra
}

\author{
History of Social Movements in the Southern Frontier:political opportunization, \\ mobilization and interpretative framework in the struggle for land
}
Historia de los movimientos sociales en la Frontera Sur: la oportunizacion política, la movilización y el marco interpretativo en la lucha por la tierra

Humberto José da Rocha

\section{Resumo}

A fronteira sul do Brasil é considerada um berço histórico de movimentos sociais de luta pela terra que são protagonistas nos dias atuais. Este artigo pretende assinalar esse processo social tendo como referencial temporal as décadas entre 1960 e 1970 . Utilizando um referencial teórico englobando além do próprio conceito de "movimento social", os conceitos de "modelo de mobilização", "repertórios", "quadros interpretativos" (frames) e "oportunização política", compomos nossa análise tendo as ideias de "estrutura" e "conjuntura" brasileiras correspondentes aos períodos abordados como contexto. $\mathrm{O}$ argumento é desenvolvido em cinco partes relacionadas: inicialmente, é apresentada a conjuntura brasileira no período considerado de modo a estabelecer um panorama para a análise. A segunda seção contextualiza a região da fronteira sul enquan- to potencial para mobilização social a partir da conjuntura nacional. A terceira seção destaca elementos teóricos para a compreensão da emergência dos movimentos na região, tendo como eixo a luta pela terra. A quarta seção discute como as mobilizações sociais se transformam em movimentos sociais coesos a partir de uma estrutura de oportunização política. A última seção resgata a trajetória dos movimentos sociais a partir da referida estruturação até os dias atuais e apresenta as considerações finais.

Palavras-chave: Atingidos por barragens. Fronteira sul do Brasil. Movimentos sociais. Sem-Terra.

* Doutor em Ciências Sociais pela Universidade Estadual de Campinas. É docente da Universidade Federal da Fronteira Sul (UFFS) no Programa de Pós Graduação em História (PPGH). E-mail: humberto.rocha@uffs.edu.br.

Recebido em 24/02/2017 - Aprovado em 31/3/2017 http://dx.doi.org/10.5335/hdtv.18n.1.6749 


\section{Estrutura e conjuntura brasileiras e a fronteira sul}

Sendo que nossa análise tem como foco as décadas de 1960 e 1970, convém apresentar de forma panorâmica o contexto social ${ }^{1}$ do período. O cenário internacional correspondia à bipolarização ideológica entre as duas grandes potências mundiais, os Estados Unidos (capitalistas) e a União Soviética (socialista). O Brasil, do ponto de vista econômico, vivia sob a égide da "ideologia desenvolvimentismo", que, em linhas gerais, corresponde a uma orientação econômica para a industrialização por meio da iniciativa privada mas que é planejada pelo Estado, que capta e orienta os recursos financeiros (BIELSCHOVSKY , 1996, p. 77). Embora o "desenvolvimentismo" tenha abrangido os anos 1930-1980, no período aqui considerado (1960-1970), a industrialização marcou o governo Juscelino Kubistchek (1956-1961) e teve sequência nos governos militares (196485), deixando bem clara a orientação desenvolvimentista. Do ponto de vista político, as restrições de direitos - sobretudo civis e políticos - podemos tomar como referência o Ato Institucional $\mathrm{n}^{\circ} 5$ (AI 5) decretado em 13 de dezembro de 1968 e revogado em 13 de outubro de 1978. O endurecimento da repressão, simbolizada pelo decreto e o posterior enfraquecimento representado, respectivamente, pela revogação, marcam um período que pode ser resumido como "passo atrás, passo adiante" no campo político brasileiro no que diz respeito à construção da cidadania (CARVALHO, 2013).

Procurando sintetizar o período, temos os seguintes elementos estruturais e conjun- turais. Em nível estrutural, considerando as duas orientações ideológicas da época (capitalismo e socialismo) e procurando nos manter no período aqui estudado, temos a deposição do então presidente João Goulart como um marco metodológico do predomínio do "capitalismo oligopolista multinacional-associado" enquanto posição ideológica brasileira em detrimento de um "nacionalismo reformista-populista-estatizante" representado nas reformas de base do ex-presidente Goulart (BRUM, 2013, p. 239-240).

Sob esta orientação, interessava ao governo brasileiro "o crescimento econômico global, não propriamente a maneira como estivesse ele distribuído entre os membros da sociedade", o que se justificava nas palavras do ministro Delfin Netto de que era preciso "primeiro é preciso fazer o bolo crescer para depois dividi-lo" (BRUM, 2013, p. 264-266). E o crescimento aconteceu, sobretudo no período conhecido como o "milagre econômico" (1968-1973), em que o país crescia na média de 10\% ao ano (BRUM, 2013, p. 288).

O período do "milagre econômico" era concomitante ao "AI 5", conformando uma conjuntura ambivalente de vantagens econômicas e restrição de direitos humanos. Esse cenário passou a se alterar gradativamente ao longo da década de 1970, tendo como marco a crise do petróleo em 1973 e a revogação do AI 5 em 1978.

Desde o final da Segunda Guerra Mundial, estava em curso a chamada "Revolução Verde", uma iniciativa de empresas norte-americanas para a modernização da agricultura mundial mediante a intensificação da mecanização e uso de adubos e defensivos 
químicos. Mas foi a partir da década de 1960 que essa modernização da agricultura chega definitivamente no Brasil que, tendo a indústria pesada instalada, pode voltar-se para a "industrialização da agricultura" com a instalação de fábricas de máquinas e insumos. Como reflexo dessa iniciativa, o governo desenvolvimentista brasileiro tendeu a criar demanda para essa indústria. Como reflexo geral do período aqui abordado temos "um aumento da concentração fundiária acompanhado de uma rápida expansão da fronteira agrícola". A modernização se percebeu no Centro-Sul e Nordeste a fronteira agrícola se expandiu principalmente para as regiões Norte (Amazônia) e Centro-Oeste (Mato Grosso e Goiás) (SILVA, 2007, p. 30-37).

A política de modernização agrícola afetou também a questão indígena no século XX e foi marcada pela ação estatal por meio do Serviço de Proteção ao Índio (SPI), que mais tarde seria substituído pela Fundação Nacional do Índio (Funai), o que não significou mudanças nas orientações da instituição. ${ }^{2} \mathrm{~A}$ ação desse órgão nesse período foi marcada, inicialmente, por uma natureza "humanista" encampada pelos irmãos Vilas Boas e pelo Marechal Rondon, no sentido da proteção aos índios. Seguindo a política desenvolvimentista, partir dos anos de 1950, esta orientação deu lugar a ações no sentido da modernização e desenvolvimentismo predominantes naquele contexto nacional, $\mathrm{e}$ que foram adotadas também em relação aos indígenas no sentido de tornar essas áreas "produtivas", no limite, exportadoras de produtos. Na década de 1970, já como FUNAI, as ações foram norteadas a partir de projetos de "integração" dos índios com a sociedade através da mecanização agrícola das terras e do arrendamento destas para colonos (TEDESCO; MARCON, 1994).

A iniciativa dos arrendamentos agravou o problema de invasão das terras indígenas por colonos - o que já acontecia desde as iniciativas colonizadoras do século XIX - que por meio desses arrendamentos avançavam além das áreas estabelecidas pelos contratos. Disso, acirrou-se o conflito entre agricultores e índios, o que aumentaria com a emergência do Movimento dos Agricultores Sem Terra (Master) a partir de 1961, que entre as suas ações ocupou Reservas Indígenas como estratégia de pressão para a reforma agrária, o que gerou a reação dos índios no sentido da expulsão dos invasores (TEDESCO; MARCON, 1994).

Outro aspecto dessa opção pela industrialização se reforçou em função da crise do petróleo de 1973 no sentido de ratificar a opção brasileira pela matriz hidrelétrica para a geração de energia. Nesse mesmo período e também como resposta à crise, o governo passou a intensificar a instalação de usinas hidrelétricas de energia (UHE) tanto que, no setor elétrico a década de 1970 é também conhecida como a década ganha, pois foi neste período que se construíram as hidrelétricas de Paulo Afonso, Três Marias e Furnas, Itai$\mathrm{pu}$, Sobradinho, Tucuruí, Salto Osório e Salto Santiago, além da UHE Passo Real, que trataremos mais adiante. Considerando a hidroeletricidade enquanto um processo social partindo da primeira hidrelétrica instalada no Brasil (1883), podemos dizer que até as décadas de 1970-80 não havia um planejamento prévio para reassentamento das famílias atingidas por barragens. Nesse período, 
o remanejamento acontecia "às vésperas da inundação" ou "quase que simultaneamente à subida das águas", conforme ocorrido nos casos de Sobradinho e Itaparica (rio São Francisco, no estado de Pernambuco), na década de 1970, e Tucuruí (rio Tocantins, no estado do Pará) e Itaipu (rio Paraná, no estado do Paraná), na década de 1980 (BERGAMASCO; NORDER, 1996).

Chegando na segunda metade da década de 1970 o crescimento econômico sustentado por empréstimos externos contraídos pelos governos militares no período aqui analisado começa a dar sinais de crise. Não obstante, o já mencionado crescimento geral dos índices econômicos do período, ocorre que os reflexos tanto da modernização agrícola quanto da instalação de hidrelétricas não têm, no aspecto social, o mesmo desempenho que no econômico, já que as populações rurais passaram a ser gradativamente expulsas das suas terras por conta do avanço das duas iniciativas desenvolvimentistas.

Ante a crise econômica, o governo militar já não tinha argumentos para sustentar a repressão dos direitos civis e políticos e a reação popular aumentava. Iniciativas para a criação do Partido dos Trabalhadores (criado em 1980), o sindicalismo combativo (no campo e cidade), a orientação da Igreja na linha da Teologia da Libertação, as Organizações de Classe (associações de professores, médicos, funcionários públicos, artistas) davam sinais de reação popular ante a conjuntura (CARVALHO, 2013, p. 178-190). Em outubro de 1978, a revogação do AI 5 significou um passo importante para a organização da popular mediante a volta dos exilados e a reorganização da classe política brasileira.

Com base nesse panorama histórico - mesmo que sucinto - podemos perceber que as décadas de 1960 e 1970 foram anos de pujança econômica brasileira se tomarmos como parâmetro os índices gerais. Sob outro ponto de vista, o desenvolvimentismo que impulsionou o campo econômico refletiu, negativamente, no campo social, já que os indicadores não refletiam necessariamente na qualidade de vida da população. Essa precariedade material ficava ainda insuportável por conta das violações dos direitos humanos pelos governos militares.

Mobilizações sociais de contestação e resistência não são exclusividade do período aqui estudado e podem ser percebidas ao longo da história brasileira. Com o olhar voltado para a construção da cidadania, Maria da Glória Gohn (2012) mapeou as principais lutas e movimentos sociais desde o século XIX quando as lutas esparsas pelo território brasileiro pautavam questões como a escravidão, tributos, o poder público e o regime político ou lutas entre categorias econômicas e pequenos camponeses até o século $X X$ quando, com o avanço da democracia e a complexidade das relações sociais, as pautas são mais difusas e os atores envolvidos pautam as questões mais claramente no sentido dos direitos humanos (GOHN, 2012).

Considerando essa trajetória mapeada pela autora, o período que abordamos no nosso estudo (1960-1970) se caracteriza, sobretudo, pela resistência ao regime militar e redemocratização (GOHN, 2012). Como vimos na seção anterior, essas pautas são agravadas pela conjuntura econômica prin- 
cipalmente depois de 1973. Embora a autora assinale inúmeros movimentos como os Estudantis, Movimentos de Guerrilha (Araguaia, Nordeste) Movimentos das Comunidades Eclesiais de Base e Pastoral da Terra, Movimentos Sindicais, Movimentos de Classes (educação, saúde) e lutas pela redemocratização e protestos pontuais (passagem de ônibus, indígenas, custo de vida), outros como os da região de Formoso e Trombas (Goiás) as Ligas Camponesas a partir de Pernambuco desde a década de 1950 (GOHN, 2012, p. 97-100) e a União dos Lavradores e Trabalhadores Agrícolas do Brasil (Ultab) fundada em São Paulo, em 1954, são fundamentais para a compreensão do processo histórico das lutas pela terra.
Não obstante a importância e a relação mútua entre as lutas e movimentos mencionados para a compreensão do processo social, nos deteremos em duas lutas e movimentos sociais ocorridos na fronteira sul do Brasil, por serem esses condizentes com o espaço, tempo e conjuntura abrangidos neste trabalho, a dizer, o sem-terra e os atingidos por barragens. A seguir, apresentamos um mapa que contextualiza essas duas lutas no âmbito do nosso estudo. Como recorte espacial, o que chamamos aqui de fronteira sul corresponde ao que está previsto na Resolução do Ministério da Integração Nacio$\mathrm{nal}^{3}$ que, conforme o mapa a seguir, em que aproveitamos para localizar as duas lutas dos movimentos sociais que passaremos a abordar:

Figura 1: Mapa da Mesorregião da Grande Fronteira do Mercosul

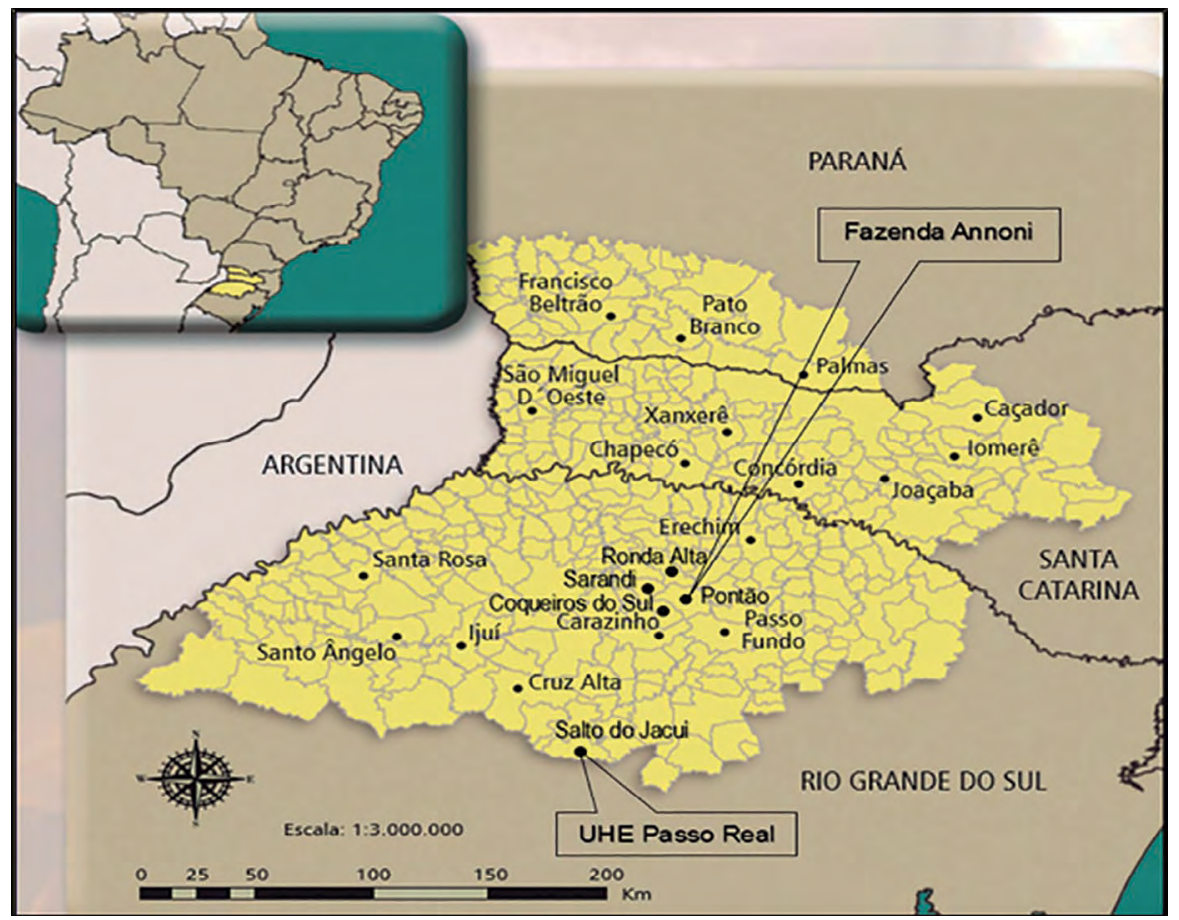

Fonte: Adaptado pelo autor a partir do Mapa da Mesorregião da Grande Fronteira Sul. Disponível em: <http://www.mi.gov.br/c/document_library/get_file?uuid=2791b4ac-40df-4fe2-b44f-6a05542052c0\&groupld=63635>. Acesso em: 15 fev. 2017. 
A região é drenada por duas bacias hidrográficas, sendo o Rio Grande do Sul e Santa Catarina drenados pela bacia do Uruguai enquanto o Paraná é drenado pela bacia do Paraná. As duas bacias juntamente com a bacia do Paraguai formam a bacia do Prata que drena, além do Brasil, o Uruguai, a Argentina, o Paraguai e a Bolívia. O relevo é planáltico predominantemente ondulado com exceção do sul da parte gaúcha, extremo leste catarinense a região de Palmas, no Paraná, onde encontram-se áreas relativamente planas. O clima é temperado com estações bem definidas.

Analisando a formação socioeconômica da região a partir dos três Estados, Corazza (2015) assinala que um primeiro traço comum foi o "longo período de isolamento da vida política e a tardia incorporação à economia nacional". A colonização aconteceu com imigrantes oriundos das "Colônias Velhas" do Rio Grande do Sul no final do século XIX que chegaram ao Oeste Catarinense nas décadas de 1930 e alcançaram o Paraná na década de 1960. As pequenas propriedades de agricultura familiar avançaram sobre áreas antes ocupadas por indígenas e caboclos. A economia de subsistência foi sendo influenciada pelo "espírito capitalista com base na propriedade privada da terra e no etos do trabalho, na busca de riqueza mas alicerçada em valores comunitários e religiosos" (CORAZZA, 2015, p. 298-299).

Os aspectos geográficos mencionados são importantes porque vão de encontro às iniciativas desenvolvimentistas dos governos brasileiros apresentadas na seção anterior. A modernização da agricultura atingiu em cheio os agricultores familiares que se viram excluídos do processo por terem propriedades de pouca extensão e em áreas onduladas, o que dificultava a mecanização. Essa pressão tecnológica também refletiu tanto na política indigenista, no sentido da "integração" desses ao capitalismo, quanto na pressão que os agricultores passaram a exercer sobre as terras indígenas. $\mathrm{O}$ mesmo fator geográfico destacou o alto potencial para exploração hidrelétrica em função dos vales destacando os rios Paraná, Iguaçu e Uruguai e seus afluentes. A conformação socioeconômica (espírito capitalista, propriedade privada da terra, etos do trabalho, busca de riqueza) e cultural (valores comunitários e religiosos) predominante nessas áreas foi outro elemento que condicionou a região como um berço potencial para movimentos de contestação da realidade da época. Nesse cenário, dois movimentos são emblemáticos por corresponderem tanto à questão da modernização agrícola quanto à instalação de hidrelétricas na região, iniciativas contestadas respectivamente por dois movimentos que surgiram na região no período aqui compreendido, a dizer, o Movimento dos Agricultores Sem-Terra (Master) e os Afogados do Passo Real.

\section{A Fronteira sul como palco de mobilização social}

Até aqui, procuramos apresentar elementos que caracterizam conjunturalmente a discussão. Utilizamos a expressão "mobilização social" pela conotação histórica implicada. De acordo com Charles Tilly o termo "mobilização" identifica o processo pelo qual um grupo passa de um coletivo passivo 
de indivíduos a um grupo participativo na vida pública". A mobilização implica ainda que o referido grupo passa a controlar recursos de cunho repressivos (armas), utilitários (dinheiro, materiais) e normativo (obrigações) que até então não controlava (TILLY, 1977, p. 3:26).

Para entendermos em que condições se dá essa mobilização, partimos do conceito de polity model para tratar as condições de mobilização a partir do exterior do grupo que se mobiliza, considerando elementos como "governo", "população" e "outros grupos" concorrentes ou aliados (TILLY, 1977, 3:1). Resgatando a análise conjuntural que apresentamos na seção anterior, basta assinalar que o governo brasileiro imprimia uma política desenvolvimentista que desfavorecia a maioria da população do campo, especialmente na fronteira sul do Brasil.

Na perspectiva do elemento "grupo" não obstante já se registrassem ainda na década de 1950 duas conferências de trabalhadores rurais organizadas pelo PCB no âmbito da Ultab, além de confrontos entre posseiros e policiais militares em São Francisco de Paula (1952), Taquara (1952 e 1953) e reivindicações de terras de um latifúndio em Erechim, esses movimentos isolados ainda não caracterizariam um grupo ou movimento coeso, mas apontavam para o seu surgimento, o que seria agravado pela crescente concentração da propriedade da terra e o esgotamento da fronteira agrícola no Rio Grande do Sul (ECKERT, 2009, p. 72-73).

Esse cenário de restrições desenvolvimentistas e mobilizações remetem à ideia de Sidney Tarrow acerca dos "ciclos de confrontos". Segundo o autor, um ciclo é notabilizado por um ou mais eventos de culminância que, para fins de análise, ajudam a catalisar os elementos que estão dispersos, mas interligados ao longo do processo social correspondente ao referido ciclo. Tarrow apresenta a sua definição do termo como sendo "uma fase de conflito acentuado que atravessa um sistema social" sendo caracterizada por "uma rápida difusão da ação coletiva de setores mais mobilizados para outros menos mobilizados", pela "criação de quadros interpretativos de ação coletiva, novos ou transformados", pela "combinação de participação organizada e não-organizada", pela capacidade de produzir "externalidades que dão aos desafiantes ao menos uma vantagem temporária e permite que superem a fraqueza na sua base de recursos". Em síntese, um ciclo de confronto "produz resultados gerais que são mais do que a soma dos resultados de um agregado de eventos desconectados", ele compreende período em que as restrições e reações se acentuam de tal forma que conformam uma unidade de análise (TARROW, 2009, p. 182).

Esse ciclo de confrontos que aqui vislumbramos tem seu marco inicial na década de 1960 no município gaúcho de Encruzilhada do Sul onde aconteceu o evento que representa um embrião da mobilização para a luta pela terra. Trezentas famílias de posseiros ocupavam uma área de 1800 hectares no município há 50 anos, quando o proprietário decidiu retomar a terra. Os posseiros então organizaram a resistência e, em 24 de junho de 1960, foi fundado naquele município o primeiro núcleo do Movimento dos Agricultores Sem-Terra (Master). O núcleo contou com o apoio do então prefeito do município, Milton Serres Rodrigues, do então superintendente da fronteira do sudoeste, Paulo Schilling e do deputado federal Ruy Ramos, todos ligados ao PTB (ECKERT, 2009, p. 73-74). 
Retomando a linha de raciocínio de Tilly, agora do ponto de vista do interior do grupo, o autor utiliza o conceito de mobilization model para analisar as possibilidades de mobilização. $\mathrm{O}$ autor elenca cinco aspectos que precisam ser considerados para a mobilização, a dizer: 1) "interesses" (as vantagens ou desvantagens comuns que possam advir para a população em questão); 2) "organização" ("a medida da identidade comum que unifica os indivíduos da população");3) "mobilização" (a quantidade e qualidade de recursos sob o controle do grupo); 4) "ação coletiva" (o grau da ação conjunta do grupo no processo de busca de fins comuns;); 5) "oportunidade" (a sintonia entre os interesses do grupo, da população e do estado atual do mundo em torno dele) (TILLY, 1977, 3:4-5).

A composição dos membros do grupo dá pistas para compreendermos os dois primeiros pontos. Segundo Córdula Eckert, estima-se que o Master buscou reunir

assalariados permanentes e temporários que, pela pouca geração de empregos no campo e pelas más condições de trabalho oferecidas, ansiavam pela posse da terra como forma de garantir a sua sobrevivência e da família; os posseiros, parceiros, arrendatários e agregados que, apesar de terem acesso à terra, o faziam de forma instável; os pequenos proprietários que, por terem parcelas de terras muito reduzidas, pretendiam ampliar sua propriedade; e os filhos desses pequenos proprietários que, ao casar, pretendiam permanecer como agricultores e para os quais nem sempre a terra do pai era sufi ciente para atender às suas necessidades (2009).

Esse registro ipsis litteris da composição do movimento, ultrapassando sua caracterização, é importante para perceber como esse perfil dos membros coincide com o perfil socioeconômico descrito anteriormente (CORAZZA, 2015) e assinala, tanto a fragilidade desses ante a política desenvolvimentista da modernização agrícola. O próprio manifesto lançado no dia da fundação do movimento reforça esses aspectos ao destacar "o entrave causado pelo monopólio da terra e a necessidade de que ela pertencesse a quem a tratava e nela trabalhava" (ECKERT, 2009, p. 74). Isso deixa clara a sintonia com os interesses e a identificação da mobilização com a população do campo especialmente na fronteira sul.

Outro ponto registrado por Eckert (2009) e que merece ser retomado foi o apoio dos políticos ligados ao PTB. Isso teve importância para o movimento porque este era o partido do então governador Leonel Brizola (ligado ao presidente João Goulart 1961-64), que apoiou o movimento. Na mesma linha, o então prefeito de Nonoai, Jair de Moura Calixto, também correligionário de Brizola, passou a apoiar ações de colonos sobre área indígenas no município.

A modernização agrícola e o esgotamento da fronteira agrícola colocaram os pequenos agricultores diante ao dilema de migrar para outras regiões ou para a cidade, ou se inserir em terras indígenas. $\mathrm{O}$ apoio do governo estadual com base na ideia de que "havia muita terra para poucos índios e que era melhor intrusar para alterar o quadro de pobreza e de demanda social dos mesmos" passou a incentivar e legitimar a intrusão de agricultores principalmente nas Reservas Indígenas de Serrinha e Nonoai, sendo que a primeira foi colonizada (TEDESCO, 2012 , p. 246-247). Sem aprofundar na ques- 
tão indígena, o importante é que isto pode ser entendido como outro reflexo da política desenvolvimentista brasileira da época e que, mais tarde vai reascender conflitos de luta pela terra na região da Fazenda Sarandi, conforme veremos mais adiante.

Quanto aos outros três elementos da análise de Tilly sobre o "mobilization model", a mobilização, ação coletiva e oportunidade, não obstante o apoio do governo do Rio Grande do Sul, segundo Eckert (2009, p. 77) "até fins de 1961, a organização do Master junto aos sem-terra era incipiente". Sendo que não temos a pretensão de aprofundar na história do MASTER, o importante aqui é assinalar a correspondência do surgimento do movimento à conjuntura que apresentamos no início do trabalho e assinalar o ponto que entendemos ser fundamental na nossa discussão, a dizer, a primeira ocupação feita pelo então fundado MASTER. Trata-se da Fazenda Sarandi, uma área de 25 mil hectares de propriedade de uruguaios que a haviam adquirido havia quarenta anos. Sob a coordenação do MASTER a área foi ocupada em 8 de janeiro de 1962 e no dia 13, quando o acampamento já somava cerca de 1.300 pessoas, o governador Brizola desapropriou a área através do decreto $n^{\circ} 14.035$. Naquela ocasião a área foi dividida em 62 lotes rurais de 25 hectares para atender a agricultura familiar e 16 propriedades de 250 hectares para agricultura mecanizada (ECKERT, 2009, p. 75-77).

A ocupação da Fazenda Sarandi em 1962, além de ser um marco histórico da luta pela terra, significa o primeiro e talvez o mais importante elemento constituinte de um "repertório" da luta pela terra. De forma genérica, o termo se refere às formas como o grupo utiliza os recursos aos quais passa a dispor (repressivos, utilitários, normativos) no contexto da mobilização. O autor assinala que o repertório de um grupo é conformado pelas circunstâncias do momento e que também tendem a evoluir segundo a trajetória da mobilização (TILLY, 1977, 5:14-15). Passados mais de 50 anos da ocupação da fazenda, sabemos que o repertório de luta pela terra compreende desde ações de conscientização e debate acerca da questão da terra até enfrentamentos físicos nas manifestações. De qualquer forma, o que ficou marcado desde o início é a "ocupação" como carro chefe do repertório de mobilização da luta pela terra.

Conforme mencionamos, o repertório de uma mobilização em determinado ciclo de confronto acontece em vista das condições internas e externas ao grupo. Um ponto que não mencionamos antes mas que também caracteriza o conjunto é o fato de que um ciclo de protestos e o respectivo repertório de mobilização faz com que o Estado "monte amplas estratégias de reação que são repressivas ou facilitadoras, ou uma combinação de ambas", (TARROW, 2009, p. 182). Na maioria das vezes, sobretudo no Brasil da década de 1960, a mobilização social corresponde a uma reação a políticas de governo, todavia, a medida da "repressão ou facilitação" do governo ante a mobilização é elemento crucial. Não significa dizer que a mobilização social está condicionada à vontade do governo, todavia, Tilly (1977, p. 4:3) defende que a medida da repressão/facilitação influencia no "custo da mobilização". Nesse sentido, a chegada dos militares ao 
governo federal e o final do governo Brizola e a chegada de Ildo Meneghetti (Partido Social Democrático - PSD) ao governo gaúcho em 1963 representou o endurecimento da repressão estatal e consequente a ausência de assentamentos sem-terra entre os anos de 1964 e 1979 o que marcou uma nova etapa para o recém-criado MASTER (TEDESCO; CARINI, 2007; ECKERT, 2009).

Tilly (1977, p. 4:3) destaca a "comunicação" e a "criminalização" como elementos que o Estado pode controlar de forma a reprimir ou facilitar a mobilização social. Aliás, o autor deixa claro que um governo não precisa ser necessariamente entendido como repressivo ou facilitador. Ocorre que na maioria das vezes os governos combinam ambos e agem de forma seletiva segundo suas intenções (TILLY, 1977, p. 4-14). No caso do governo Brizola, o que era visto como favorável aos agricultores não tinha a mesma conotação na perspectiva indígena, por exemplo (TEDESCO; MARCON, 1994). Já no governo, Meneghetti, para mencionar apenas o Rio Grande do Sul, a repressão e a contrainformação praticamente inviabilizaram a mobilização social no período entre 1964-79, todavia, grandes madeireiros, granjeiros, industriais e comerciantes regionais foram beneficiados (TEDESCO; CARINI, 2007).

No conjunto da análise, esta seção procurou relacionar a narrativa histórica e elementos teóricos para dar pistas de como aconteceu a mobilização social de luta pela terra a partir da "polity model" desenvolvimentista. O agravamento da situação, especialmente no campo econômico fez emergir um "ciclo de confronto" em que a mobili- zação social simbolizada pela formação do MASTER no início da década de 1960 deixa perceber que o principal recurso do "repertório" seria a "ocupação de terra". Consequentemente, o governo reage à mobilização e reprime a luta pela terra. Este período de inanição da luta foi também de aglutinação de forças que viriam a eclodir futuramente num outro ciclo de protestos. Na próxima seção analisaremos como a luta pela terra se estabeleceu como eixo aglutinador de diferentes grupos.

\section{0 masterframer da Luta pela Terra}

A ocupação e o decreto de desapropriação da Fazenda Sarandi foram marcos importantes na luta pela terra no Brasil por demonstrar o poder de mobilização do MASTER. Todavia, a mudança conjuntural no Rio Grande do Sul e os "anos de chumbo" da ditadura militar colocariam à prova tal mobilização. Partindo do MASTER como referência, embora este não tenha conseguido ganhos substanciais a partir do seu repertório de ações, novos elementos passaram a constituir o ciclo de confronto de forma que uma "indústria de movimentos sociais" pode ser percebida na época.

Assim como Tilly, McCarthy e Zald (1977) analisam a mobilização de recursos só que acrescentam ideias que ajudam a compreender esta fase da luta pela terra. Partindo da ideia genérica de "movimento social" enquanto a conformação de um conjunto de opiniões e crenças que buscam mudanças em alguns elementos estruturais ou de distribuição de recompensas de uma determinada sociedade, os autores explicam 
que este movimento social não aparece espontaneamente, ele corresponde a uma "organização complexa e formal, que identifica suas metas com as preferências de um movimento ou mesmo de um contra movimento, e tenta implementar essas metas", (social movement organization - SMO), assim, um movimento social mobiliza recursos para se organizar (MCCARTHY; ZALD, 1977, p. 1218). Seguindo no raciocínio é que os autores chegam ao conceito de "indústria de movimentos sociais" (social movement industry - SMI), que é quando diferentes movimentos sociais procuram se identificar com um maior número de preferências e objetivos em relação a outros movimentos (MCCARTHY; ZALD, 1977, p. 1219).

Essa "indústria" (SMI) teve na própria política desenvolvimentista brasileira uma importante fornecedora de matéria-prima. A partir da segunda metade da década de 1960 começaram os trabalhos de instalação da Usina Hidrelétrica Passo Real, no Rio Jacuí, com a barragem e casa de força localizadas no município de Salto do Jacuí-RS. A barragem com 58 metros de altura e 715 metros de comprimento criou um reservatório de $233,39 \mathrm{~km}^{2}$ (aproximadamente $24 \mathrm{mil}$ hectares) atingindo de oito municípios gaúchos: Alto Alegre, Campos Borges, Fortaleza dos Valos, Ibirubá, Jacuizinho, Quinze de Novembro, Salto do Jacuí e Selbach. As seis comportas e duas turbinas tipo Kaplan (eixo vertical) configuram uma potência de 158 MW. Gerenciada pela Companhia Estadual de Geração e Transmissão de Energia Elétrica (CEEE), as unidades 1 e 2 entraram em operação, respectivamente, em 17 de março e 20 de junho de 1973, sendo sua inaugura- ção em 25 de setembro de 1973 (CEEE, 2011, 1-2).

A UHE Passo Real apresenta o maior reservatório do Rio Grande do Sul. Os aproximados 24 mil hectares inundados para uma geração máxima de $158 \mathrm{MW}$ resulta em índice hectare/MW de 157,48. Esta relação indica que cada hectare inundado gera 0,006 MW, o que aponta para "o pior caso de aproveitamento espacial hidrelétrico" se comparado a outras hidrelétricas da bacia (CARVALHO, 2006, p. 112). Esse dado se sustenta pela comparação tanto com hidrelétricas maiores e mais recentes quanto com a UHE Passo Fundo, por exemplo, de tamanho semelhante e instalada na mesma época da UHE Passo Real.

A instalação da UHE Passo Real implicaria no remanejamento populacional das famílias atingidas. Alegando incapacidade para tratar da questão social, a CEEE transferiu a responsabilidade para o Instituto Nacional de Colonização e Reforma Agrária (Incra) mediante um Acordo de cooperação em 28 de agosto de 1967. Um mês depois o Incra procedeu o levantamento da população atingida apontando um universo de 1452 famílias potencialmente atingidas sendo: 798 proprietários de terras; 454 parceiros; 62 posseiros; 43 arrendatários e 104 assalariados. Sendo que se pretendia iniciar o enchimento do lago em julho de 1970, o Incra promoveu o remanejamento de 523 famílias numa área de 16.449,36 hectares dividida em lotes que variavam entre 24 e 54 hectares abrangendo três fazendas (104 famílias na fazenda Colorado, 313 famílias na Boa Vista e 106 famílias na Itaíba) nos municípios de Cruz Alta, Santa Bárbara do Sul e 
Ibirubá mediante o Decreto Presidencial ${ }^{\circ}$ 64.485 de 9 de maio de 1969 (DARÓS, 1973, p. 43-45).

Seguindo no projeto, em 24 de março de 1972 o Incra procedeu a desapropriação da Fazenda Annoni prevendo a divisão da área em aproximadamente 200 lotes com áreas entre 20 e 30 hectares e destinaria 2.200 hectares como reserva legal sob domínio público. Passados dois anos, dos duzentos lotes previstos, apenas 30 famílias de "afogados" haviam sido reassentadas na área juntamente com outras 24 famílias de empregados do antigo latifúndio desapropriado. O processo foi interrompido por conta da judicialização de uma ação por parte dos proprietários, o que retardou o desfecho até 1986 (BONAVIGO; BAVARESCO, 2008 , p. 33-37).

Além da Fazenda Annoni o Incra passou a organizar reassentamentos provisórios nas fazendas Sagrisa, Macali e Sertão, outras famílias foram indenizadas em dinheiro e as que não foram contempladas passaram a formar acampamentos nos municípios de Carazinho (70 famílias nas margens do Rio Bonito), Fortaleza dos Valos (367 pessoas no Capão Bonito), Ronda Alta (117 pessoas no Cemapa) e Cruz Alta (50 pessoas no Frei Caneca) (BENINCÁ, 1987, p. 64-66).

Dessa forma, a UHE Passo Real forneceria outro substrato para a chamada "indústria de movimentos sociais" na fronteira sul. Além dos agricultores sem-terra em função da modernização agrícola, os projetos de grande escala, a partir da inundação de 24 mil hectares, despejava mais outra leva de sem-terra que, pela natureza da perda, ficaram conhecidos como "afogados do Passo Real".
A relação entre os conceitos de "ciclos de protestos" (TARROW, 2009) e "SMI" (MCCARTHY; ZALD, 1977) vai ajudar a compreender como a mobilização social vai ganhando unidade com o passar do tempo, apesar da repressão estatal a partir de 1964. Para avançarmos para o entendimento de qual seria o eixo dessa unidade, o conceito de "framer" elaborado por David A. Snow e Robert D. Benford a partir dos conceitos anteriores se faz importante.

A palavra "framer" remete à ideia de "quadro" ou "moldura" que metaforicamente sugere "um esquema interpretativo que simplifica e condensa o mundo lá fora pontuando seletivamente e codificando objetos, situações, eventos, experiências e sequências de ações dentro do ambiente presente ou passado". Segundo os autores, num cenário de ação coletiva a importância de um "framer" está nas capacidades de "atribuição e articulação". Na esfera da atribuição, a referência de um framer ajuda nos diagnósticos (identificação) e prognósticos (resolução) de problemas. Já na esfera da articulação, o framer funcionaria no sentido de alinhar elementos constituindo uma ordem significativa (SNOW; BENFORD, 1992, p. 137-8), o que, segundo McCarthy e Zald (1977, p. 155) seria buscado entre os grupos que demonstrem uma "consciência aderen$\mathrm{te}^{\prime \prime}$.

Assim, o conceito de framer se aproxima do SMO por fazer referência a um grupo específico que busca atribuição e articulação no mundo social. No caso aqui estudado, o MASTER procurou reunir pessoas que de certa forma perderam suas terras em função do desenvolvimentismo que ao modernizar 
a agricultura os excluía. $\mathrm{O}$ advento da hidrelétrica de Passo Real colocou em cena o grupo dos "afogados" que também lutavam contra a perda das suas terras, mesmo que por outros motivos. Nessa luta, 60 famílias que não foram contempladas ou tinham seu reconhecimento de seus direitos negados pelo Incra no Passo Real, ocuparam a Fazenda Annoni e junto com "Sem Terra" formaram um acampamento em 1976 (BENINCÁ, 1987, p. 65).

Aqui a "indústria dos movimentos sociais" encontra substratos em dois SMO (MCCARTHY; ZALD, 1977) ou frames (SNOW; BENFORD, 1992) que se aproximam através do que os segundos chamam de "master framer". O conceito de master framer funciona da mesma forma que o framer, todavia, ele é mais genérico, catalizador e acontece em maior escala (SNOW; BENFORD, 1992, p. 138). A mudança de escala implica na variedade maior de recursos e objetivos inter-relacionados, assim, o potencial aglutinador de um master frame depende de variáveis como capacidade de atribuição, sua fidelidade ou centralidade narrativa e sua credibilidade empírica ou comensurabilidade experimental (SNOW; BENFORD, 1992, p. 138).

Geograficamente falando, os caminhos dos "sem-terra" do MASTER que o ocuparam as Fazendas Macali e Brilhante no início dos anos 1960 e dos "afogados" do Passo Real que pretendiam a Fazenda Annoni no final da mesma década se aproximaram na antiga Fazenda Sarandi, se considerarmos as três fazendas em seu conjunto. Já na perspectiva da mobilização social, a luta pela ter- ra parece corresponder ao master frame que identifica esses dois movimentos.

Observando o potencial aglutinador deste master frame a partir dos pontos citados por Snow e Benford, podemos dizer que a "luta pela terra" seria o "master frame" que identificaria afogados e sem-terra. No tocante à "atribuição" ambos identificam a modernização ou industrialização e concentração fundiária como problemas que teriam como solução a reforma agrária. No campo da articulação, o fato de ambos serem expropriados por uma política desenvolvimentista confere fidelidade e credibilidade para uma narrativa de sofrimento e luta que condizia com a realidade empírica daqueles que por um ou outro motivo acabaram acampados conformando este quadro.

Nesta seção apresentamos as mobilizações desde a emergência dos "afogados do passo real", a partir da segunda metade da década de 1960 até a ocupação da fazenda Annoni por eles na segunda metade da década de 1970. Esse período condiz com os chamados "milagre econômico" e "anos de chumbo" que representaram, respectivamente, facilitação e repressão na história do Brasil. Para a análise na perspectiva dos movimentos sociais, três conceitos desenvolvidos até aqui merecem ser resgatados para encaminharmos esta seção, "ciclo de protesto", "repertórios" e "master frames".

As relações que Snow e Benford (1992) estabelecem entre esses três conceitos são elucidativas para nossa análise. Segundo os autores, um master frame está associado à emergência de um ciclo de protesto (SNOW; BENFORD, 1992, p. 142). Quanto à relação entre os movimentos no master frame, os 
mesmos defendem que aqueles movimentos que emergem cedo em um ciclo de protestos tendem a ser progenitores do master frame, ao passo em que os movimentos tardios tendem a ficar mais restritos no enquadramento deste (SNOW; BENFORD, 1992, p. 144-5). Na mesma linha, a emergência de novos master frames tendem a gerar novas táticas repertórios de mobilização (SNOW; BENFORD, 1992, p. 146).

Essas colocações, mesmo que tratadas aqui sumariamente, servem para explicar que o ciclo de protestos inaugurado a partir de meados da década de 1960 inaugurou um novo master frame a partir da luta pela democracia ou contra a ditadura. No tocante ao meio rural, não obstante a influência deste quadro, a "luta pela terra" passou a ser o master frame que identificou "sem terras" e "afogados" o predomínio do elemento terra sobre o elemento água é compreensível tanto pela "credibilidade empírica", pois foi terra que se perdeu com a inundação pela hidrelétrica, quanto pelo fato de que o Master "atribuiu" à terra - ou à má distribuição desta - a causa e solução para o problema social brasileiro. Dessa forma, este master frame influenciou no repertório dos movimentos tornando a ocupação de terras a sua marca registrada. Essa tática que havia minguado em função dos "anos de chumbo" retornaria em função de um quadro de "oportunização política" elemento teórico que norteará a próxima seção deste trabalho.

\section{A oportunização política para a consolidação da luta pela terra}

A luta pela terra pode ser compreendida como um master frame que aglutinou grupos e orientou um repertório que tinha nas ocupações sua principal tática de ação. Os "anos de chumbo", que consideraremos aqui com vistas à publicação e suspensão do Ato Adicional nº 5 (AI-5), compreenderam um período em que a luta pela terra sofreu forte repressão e avançou menos em termos de conquistas em comparação a outros períodos.

A retomada da luta pela terra tomaria novo impulso no final da década de 1970 a partir de um cenário que vai ao encontro do que Sidney Tarrow define como "estrutura de oportunidades políticas" (EOP), que visa compreender como demandas de grupos são manifestadas diante de um cenário oportuno, dando origem, então, a "confrontos políticos". Sustenta o autor que num cenário de oportunização "o confronto político surge como uma reação a mudanças nas oportunidades e restrições políticas em que os participantes reagem a uma variedade de incentivos: materiais e ideológicos, partidários ou baseados no grupo, de longa duração ou episódicos" (TARROW, 2009, p. 38).

Mas um cenário de oportunidades não significa, necessariamente, que confrontos políticos venham a ocorrer. Mesmo diante das demandas dos grupos - sejam pontuais ou estruturais - há que se distinguir entre "potencial de mobilização" e "ação" de fato. O primeiro representa o estado de latência do confronto, enquanto o segundo representa a mobilização efetiva que o promove. Nes- 
se sentido, Tarrow apresenta cinco aspectos a serem observados de forma a percebermos como essa passagem de potencial em ação pode acontecer de maneira geral: "1) abertura do acesso à participação para novos atores; 2) a evidência de realinhamento político no interior do sistema; 3 ) a presença de aliados influentes; 4) divisões emergentes no interior da elite; 5) um declínio na capacidade do estado de reprimir dissidências" (TARROW, 2009, p. 105), vejamos como isso pode ser identificado.

Retomando a história do Brasil, esse quadro de "oportunização" corresponde ao período em que o poder de repressão do Estado foi aos poucos diminuindo em relação aos chamados "anos de chumbo", auge do período militar. A revogação do AI 5 (outubro de 1978), a Lei da Anistia (agosto de 1979) e o fim do bipartidarismo (novembro de 1979) permitiram a volta dos exilados políticos para o país reforçando o ativismo nas diversas causas sociais, promoveram a divisão das elites acarretando assim no enfraquecimento de oligarquias, o realinhamento político e o fortalecimento da sociedade civil.

De acordo com o panorama histórico que apresentamos na primeira seção, há que se considerar que o enfraquecimento do regime militar, não obstante as lutas pela redemocratização, passa pela dificuldade econômica do final do ciclo desenvolvimentista brasileiro (1930-80). Os seguidos anos de crescimento e as iniciativas de modernização (agricultura e projetos de grande escala) sustentadas por financiamentos exteriores ficaram comprometidas em função da crise do petróleo de 1979 que afetou o mundo in- teiro e no Brasil inaugurou um novo período econômico de crise (CARNEIRO, 2006). Dessa forma, o regime ditatorial já não contava com a pujança econômica para contrabalançar com a repressão, o que configurou um período de abertura política em que se abriu espaço para participação de novos atores a passo que a repressão ficou menor.

Concentrando a discussão na luta pela terra, no campo político institucional no estado do Rio Grande do Sul são notórios os trabalhos da Assembleia Legislativa de investigação parlamentar sobre a Fazenda Sarandi (1979) e sobre a questão das barragens em 1983 (TEDESCO; CARINI, 2007; ROTHMAN, 1996). Nesse mesmo período há que se registrar outro realinhamento político importante, a criação do Partido dos Trabalhadores (PT) que passaria a caminhar lado a lado com os movimentos sociais no período.

Quanto à luta pela terra propriamente, segundo Tedesco e Carini, o norte gaúcho esboçaria, "a partir do começo de 1978, um novo (velho) cenário de lutas envolvendo a questão da terra, resultado de problemas iniciados nos idos de 1960 e não resolvidos satisfatoriamente pelo estado brasileiro" (TEDESCO; CARINI, 2007, p. 137). Ocorreu que o mesmo ambiente de oportunização política reascenderia a questão indígena de Nonoai que se estendia desde o início da década de 1960 e que comentamos na segunda seção. Ocorreu que no final de 1977 assume na reserva de Nonoai um cacique pertencente a uma ala que defendia o confronto com os agricultores intrusos. Além disso, além da conscientização dos próprios indígenas, diferentes grupos aderiram à causa indígena 
tais como organizações nacionais e internacionais, antropólogos, indigenistas, ecologistas e sociólogos. Fato é que, em maio de 1978 , os indígenas passaram a intimidar os agricultores da reserva, escolas foram incendiadas e finalmente os agricultores foram expulsos pelos índios da reserva de Nonoai (TEDESCO, 2012, p. 251-252).

As famílias expulsas passariam a integrar a massa sem-terra da época. Em meados de 1978, 37 famílias oriundas do conflito de Nonoai ocupam a reserva florestal da Fazenda Sarandi. Com o passar do tempo mais famílias foram se somando e o grupo decide ocupar a gleba Macalli em 6 de setembro de 1979 e em 25, 26 e 27 passaram a ocupar também a gleba Brilhante (TEDESCO, 2012, p. 255-256). Em vista de que a ocupação das glebas Macali e Brilhante não absorveria todo o contingente sem-terra, as famílias não contempladas nessas áreas tentaram ocupar a Fazenda Annoni em outubro de 1980, mas não tiveram o mesmo sucesso ante forte vigilância policial por conta da tensão na região (TEDESCO, 2012, p. 256-257).

Dois meses depois, a família de Alberto Natálio Vargas não contemplada nas ocupações na Macali e Brilhante armou a primeira barraca na Encruzilhada Natalino em 8 de dezembro de 1980. A partir disso se desenvolveu o "Acampamento Natalino" em quatro fases desde a primeira barraca: 1 ) dezembro/80 até julho/81 (gestão do acampamento); 2) julho e agosto/81 (intervenção militar na área); 3) março/82 (assentamento provisório em Nova Ronda Alta); 4) outubro/1983 (assentamento definitivo em Nova Ronda Alta) (MARCON, 1997 , p. 66-67).
Em meio a esse cenário de oportunização que foram fundados, definitivamente dois movimentos sociais de expressão na luta pela terra, o MST e o MAB. As ocupações de terras realizadas nos estados de Santa Catarina, Paraná, São Paulo, Mato Grosso do Sul, e, sobretudo, no Rio Grande do Sul, resultaram na fundação do Movimento dos Trabalhadores Rurais Sem-Terra (MST) durante o I Encontro Nacional do MST, realizado em Cascavel-PR, entre 21 e 24 de Janeiro de 1984. A questão dos " afogados do Passo Real e a divulgação de que a Eletrosul pretendia instalar 25 hidrelétricas na bacia do Uruguai levou à fundação da Comissão Regional de Barragens (Crab) em Concórdia, SC, no dia 24 de abril de 1979, que passou a responder como MAB/Região Sul desde março de 1991, quando se oficializou o Movimento dos Atingidos por Barragens (MAB) durante o "I Congresso Nacional dos Atingidos por Barragens" em Brasília.

Embora nosso objetivo principal seja analisar os movimentos sociais de luta pela terra, é importante ressaltar que o cenário de oportunização política permitiu a articulação de pessoas e instituições tais como: intelectuais, setores de universidades, políticos e alas de partidos políticos, sindicatos combativos, organizações da sociedade civil tais como a CNBB, a OAB e a ABI, segmentos das Igrejas Católica e Luterana além de organizações internacionais, de forma que a luta pela terra embora protagonizada pelos agricultores contou com um importante suporte material e ideológico que ajudou a conformar os repertórios dos movimentos sociais de luta pela terra. Dessa forma, A formação da Crab e depois do MAB tem nos 
"afogados do Passo Real uma importante referência na estruturação. Os atingidos pela UHE Itaipu, no Paraná também se aproximaram do Mastro e acabaram, de certa forma, ajudando na estruturação do MST que tem nas ações do Master, Encruzilhada Natalino e Annoni, importantes elementos da sua formação (ROTHMAN, 1996; FERNANDES, 2000).

Voltando para o Acampamento Natalino, foi na terceira fase do acampamento, quando a vigilância militar já não era a mesma, que os "afogados" se juntaram aos "sem-terra" nesse acampamento, formando uma "Comissão dos Sem-terra do Passo Real". As atividades de mobilização e reflexão entre os "afogados" acampados do Natalino e os "sem-terra" da Nova Ronda Alta "permitiram que as bandeiras de luta fossem ampliadas", tanto que no I Encontro Nacional do MST (Goiânia, em setembro de 1982) a Comissão Regional do Rio Grande do Sul elencou dentre as prioridades a questão dos "afogados do Passo Real". No plano prático, já se preparava uma ocupação sobre a Fazenda Annoni. Em 1983, os "afogados" ocupam novamente a Annoni tratam de demarcar lotes e começar algum plantio, todavia, a falta de insumos e implementos - não obstante o apoio do MST e da Igreja - e o envolvimento na manutenção e na defesa da ocupação impediram que conseguissem sequer a primeira colheita e a ocupação fracassou (IOKOI, 1991, p. 65-68).

A partir dessa aproximação de "sem-terra" e de "afogados" na "luta pela terra" várias ações de ocupações tanto relativas a propriedades quanto a órgãos públicos foram registradas nos anos seguintes. Sob outro ponto de vista, há que se registrar que, como em qualquer movimento social, é difícil uma homogeneidade e as disputas internas também foram elementos marcantes dessa articulação. A ocupação de, aproximadamente, 1500 famílias de "sem-terra" na "Área 10" da Fazenda Annoni, em 29 outubro de 1985, teve como aspecto marcante a iniciativa dos acampados de "espalhar pessoas por toda a área, tendo como objetivo impedir a entrada dos 'afogados' que ameaçavam montar acampamento em algum ponto da fazenda". A ação do Exército acabou com o "espalhamento na área" e essa fragilização da ocupação facilitou uma nova ocupação de cerca de 50 famílias de "afogados" na Fazenda Annoni em janeiro de 1986, também sem sucesso (BONAVIGO; BAVARESCO, 2008, p. 36-37).

Nessa altura dos acontecimentos a Fazenda Annoni já representava um palco de luta pela terra de repercussão internacional. A abertura democrática favoreceu os diálogos e a conformação da superintendência regional do Incra já demonstrava simpatia com a causa, tanto que em 1987 iniciam os reassentamentos definitivos na Fazenda Annoni, o que aconteceu em quatro fases: Fase 1 (1987): assentamento de 57 famílias de "afogados" e 35 famílias de "sem-terra" na área conhecida como "Assentamento Holandês"; Fase 2 (1987): assentamento de 35 famílias de "sem-terra" no "Holandês"; Fase 3 (1987): assentamento de 30 famílias de ex-empregados da Fazenda Annoni na área conhecida como "Rio Bonito"; Fase 4 (1989): assentamento de 81 famílias na área conhecida como "16 de Março", 45 famílias na “Área 5", 43 famílias na "Área 9" e 63 
famílias na "Área 10" (BONAVIGO; BAVARESCO, 2008, p. 44-47).

O processo de ocupação e assentamento na Annoni aglutinou na "luta pela terra" "afogados" e "sem-terras" evidenciando os pontos comuns entre as diferentes demandas e as diferenças de interesses. Para além da diferença entre "afogados" e "sem-terra" evidenciada nas ocupações de 1985-86, se considerarmos apenas a categoria de "sem-terra", os distintos interesses promoveram um racha interno que resultou na organização da "Associação Gaúcha de Reforma Agrária" (Agra). Ocorreu que na organização da terceira fase do processo de assentamento um grupo de acampados descontentes com os critérios de distribuição dos lotes pelo MST e Incra criaram a Agra e passaram a disputar com o MST a coordenação dos acampamentos. Embora esse grupo não tivesse logrado a hegemonia nos assentamentos, o que importa aqui é o fato da contradição interna no movimento (BONAVIGO; BAVARESCO, 2008, p. 45).

A conquista da Fazenda Annoni representa um marco internacional da luta pela terra. Em nível de movimentos sociais, representa um marco espacial que aglutinou aqueles que perderam suas terras, seja pela instalação de Projetos de grande escala como as hidrelétricas quanto pela industrialização da agricultura. Desde o final do processo de reassentamentos na Annoni, já num ambiente político democrático, os movimentos sociais seguiram trajetórias próprias mas estabelecendo uma identidade de luta pela terra que se forjou ao longo do processo histórico que buscamos apresentar.

\section{Expansão da luta pela terra a partir da}

\section{fronteira sul do Brasil}

James M. Jasper conceitua o termo "movimentos sociais" como sendo "esforços persistentes e intencionais para promover ou obstruir mudanças jurídicas e sociais de longo alcance, basicamente fora dos canais institucionais sancionados pelas autoridades".

Embora seja recomendável iniciar a discussão pela apresentação conceitual, preferimos aqui construir um caminho entre a narrativa histórica e a discussão teórico-conceitual que permitisse demonstrar como a luta pela terra se consolidou na fronteira sul do Brasil. A "persistência" assinalada por Jasper difere o movimento social de "eventos isolados", a "intencionalidade" indica que um movimento social implica "cultura e estratégia" para "promover", no caso da luta pela terra, as mudanças sociais e jurídicas pela via não institucional, para mencionar o próprio movimento, sem esquecer as relações com partidos políticos e grupos de interesses dos quais se diferem (JASPER, 2016, p. 23-24).

Sendo que o governo brasileiro imprimiu uma política desenvolvimentista desde a década de 1930, foi nos anos de 1950 quando a chamada "Revolução Verde" tratou de modernizar a agricultura, estreitando a fronteira agrícola e promovendo conflitos entre indígenas e agricultores e depois os Projetos de Grande Escala que expropriavam por meio da inundação que começou a se registrar mobilizações mesmo que esparsas. Essa "mobilização" se deu a partir de "ciclos de confronto" em que os "repertórios" corres- 
pondem à "intencionalidade" de resistir e "promover a mudança" dessa realidade.

O início da década de 1960 foi marcado pela criação do Master que passou a ser referência na luta pela terra e apresentou um "repertório" que teria nas ocupações de terras sua principal expressão. A instauração de um regime militar ditatorial em 1964 abafou as ações do Master e os chamados "anos de chumbo" representaram uma estagnação na trajetória de mobilizações. Nesse período, a instalação de uma barragem no rio Jacuí fomentou a mobilização dos "afogados do Passo Real" que se identificaram com o Master sob o master frame da "luta pela terra". Embora reprimida, a "indústria de movimentos sociais" não fechou, por assim dizer, ela reuniu subsídios que seriam importantes em momento oportuno.

A "oportunidade" veio no final da década de 1970 com o enfraquecimento do regime militar, por conta da mobilização a partir de um master frame mais amplo que era a democratização que reuniu diferentes segmentos da sociedade, mas, também, em função do esgotamento do modelo desenvolvimentista. A partir da questão indígena, um novo "ciclo de protestos" inicia no sul do país e os "repertórios" de luta pela terra são reativados e têm lugar principalmente no Acampamento Natalino e na Fazenda Annoni, que passariam a simbolizar a luta pela terra internacionalmente.

Foi neste "ciclo de protestos" que a "intencionalidade e persistência" que marcou todo o processo histórico de mobilizações desde a década de 1950 convergiram para a criação do MST em 1982 e do MAB em 1991. É possível considerar esses movi- mentos sociais anteriormente a essas datas, todavia, foi a partir desses momentos que a luta pela terra passou a contar com o protagonismo e a referência desses de forma definitivamente persistente reforçando suas bandeiras específicas paralelamente à identificação em torno da luta pela terra.

A complexidade da questão da terra no Brasil, intercruzada por aspectos econômicos, culturais e políticos fez emergir outros movimentos de expressão como o MPA (Movimento dos Pequenos Agricultores) e o MMC (Movimento de Mulheres Camponesas) oriundos de mobilização no âmbito dos movimentos anteriores que construindo suas bandeiras específicas e ampliando o master frame da luta pela terra. Num outro estágio de desenvolvimento, esses movimentos formalizaram essa articulação em maio de 1993 por ocasião da I Conferência da "Via Campesina", em Mons (Bélgica). Esse movimento de abrangência internacional reúne organizações camponesas de pequenos e médios produtores, mulheres rurais, comunidades indígenas, sem-terra, jovens rurais e trabalhadores agrícolas migrantes nos cinco continentes. Para os dirigentes, a Via campesina representa "uma continuidade entre as lutas dos anos 1960, 1970, 1980", especialmente no que se refere aos eventos ocorridos no norte do Rio Grande do Sul (VIEIRA, 2011, p. 180-181).

O processo histórico que originou movimentos sociais de luta pela terra ainda contabiliza tanto refluxos como as divisões internas e criminalizações quanto conquistas como a chegada do PT ao governo federal. São momentos que impõem desafios, criam esperanças e geram frustrações que fazem com que esses movimentos sociais 
permaneçam em constante atualização. O que pretendemos demonstrar aqui foi como esse processo aconteceu a partir da fronteira sul do Brasil.

\begin{abstract}
The Southern Frontier of Brazil is considered a historical cradle of social movements fighting for land that are protagonists in the present day. This article intends to point out this social process, having as a temporal reference the 1960s and 1980s. Using a theoretical framework encompassing the concept of "social movement", the concepts of "mobilization model", "repertoires", "frames" and "Political Opportunization", we compose our analysis having the ideas of Brazilian "structure" and "conjuncture" corresponding to the periods covered as background. The argument is developed in five related parts: initially the Brazilian conjuncture is presented in the considered period in order to establish a background for the analysis. The second section contextualizes the South Frontier region as a potential for social mobilization from the national conjuncture. The third section highlights theoretical elements for the understanding of the emergence of movements in the region having as its axis the struggle for land. The fourth section discusses how social mobilizations become social movements cohesive from a structure of political opportunization. The last section recalls the trajectory of social movements from the aforementioned structuring to the present day and presents the final considerations.
\end{abstract}

Keywords: Affected by Dams. Landless. Social Movements. Southern Frontier of Brazil.

\section{Resumen}

La frontera Sur de Brasil es considerado una cuna histórica de los movimientos sociales que luchan por la tierra que son protagonistas hoy. Este artículo tiene la intención de marcar este proceso social que tiene como referencia temporal de los años 1960 y 1980, utilizando un marco teórico que abarca más allá del concepto de "movimiento social", los conceptos de "modelo de movilización", "repertorios", "marcos interpretativos" (frames) y "oportunizacion política" que componen nuestro análisis con las ideas de "estructura" y "coyuntura" brasileñas durante los períodos cubiertos como telón de fondo. El argumento se desarrolla en cinco partes relacionadas: se presentó por primera vez la situación de Brasil durante el período considerado, con el fin de establecer un fondo de tela para el análisis. La segunda sección contextualiza la región de la Frontera Sur como un potencial de movilización social de la situación nacional. La tercera sección se destacan elementos teóricos para la comprensión de la aparición de los movimientos de la región teniendo como eje la lucha por la tierra. La cuarta sección se analiza cómo las movilizaciones sociales se transforman en movimientos sociales cohesivos de una estructura de oportunizacion política. La última sección se recupera la historia de los movimientos sociales de esa organización hasta la actualidad y presenta las consideraciones finales.

Palabras-clave: Afectados por Represas. Frontera Sur de Brasil. Movimientos Sociales. Sin Tierra. 


\section{Notas}

1 Este "social" é digno de nota por se referir a "História Social" defendida pelos Annales. De acordo com os fundadores da revista, o termo social remeteria à unidade de análise que engloba diferentes aspectos tais como o econômico e o social (CARDOSO, 2002, p. 348-350).

2 O Serviço de Proteção ao Índio (SPI) foi criado pelo Decreto $\mathrm{n}^{\circ}$ 8.072, de 20 de junho de 1910, sendo substituído pela Fundação Nacional do Índio (FUNAI) através da Lei $\mathrm{n}^{\circ} 5.371,5$ de dezembro de 1967.

3 A MESORREGIÃO DA GRANDE FRONTEIRA DO MERCOSUL foi criada no âmbito do Decreto Presidencial $n^{\circ}$ 6.047, de 22 de fevereiro de 2007, que instituiu a Política Nacional de Desenvolvimento Regional (PNDR) (BRASIL, 2007). De acordo com o Ministério da Integração Nacional, a Mesorregião Grande Fronteira do Mercosul “compreende 396 municípios, sendo 223 no norte do Rio Grande do Sul, 131 no oeste de Santa Catarina e 42 no sudoeste do Paraná. Possui uma área total de $120.763 \mathrm{~km}^{2}$ e população de 3.815 .791 habitantes (estimativa de 2007 - IBGE)" (BRASIL, 2009, p. 31).

\section{Referências}

BENINCÁ, Elli. Conflito religioso e práxis: a ação política dos acampamentos de Encruzilhada Natalino e Fazenda Annoni e o conflito religioso. 1987. Dissertação (Mestrado em Ciências da Religião) - Pontifícia Universidade Católica de São Paulo, São Paulo, 1987.

BERGAMASCO, Sônia Maria; NORBER, Luiz Antônio Cabello. O que são re-assentamentos rurais. São Paulo, Brasiliense, 1996.

BIELSCHOWSKY, Ricardo. Pensamento econômico brasileiro. O ciclo ideológico do desenvolvimentismo. 3. ed. Rio de Janeiro: Contraponto, 1996.

BONAVIGO, Elisabete Ana. BAVARESCO, Pedro Antônio. Fazenda Annoni: da ocupação ao assentamento definitivo. In: TEDESCO, João Carlos. Conflitos agrários no norte gaúcho-1980-2008. Passo Fundo: Ediupf, 2008.
BRASIL. Decreto $n^{\circ}$ 6.047, de 22 de Fevereiro de 2007. Institui a Política Nacional de Desenvolvimento Regional - PNDR e dá outras providências. Disponível em: <http:/ / www.planalto.gov.br/ccivil_03/_ato2007-2010/2007/ decreto/D6047.htm>. Acesso em 15 fev. 2017.

Ministério da Integração Nacional. Programa de Promoção da Sustentabilidade de Espaços Sub-Regionais (PROMESO). Brasília-DF, 2009. Disponível em: <www.integracao.gov.br >. Acesso em 15 fev. 2017.

BRUM, Argemiro J. O desenvolvimento econômico Brasileiro. 28. ed. Petrópolis: Vozes, 2013.

CARNEIRO, R. Desenvolvimento em crise: a economia brasileira no último quarto do século XX. 2. ed. São Paulo: Unesp, 2006.

CARVALHO, José Murilo de. Cidadania no Brasil: o longo caminho. 16. ed. Rio de Janeiro: Civilização Brasileira, 2013.

CARVALHO, Orlando Albani de. Água sobre terra: lugar e territorialidade na implantação de grandes hidrelétricas. Dissertação (Mestrado em Geografia) - Universidade Federal do Rio Grande do Sul, Porto Alegre, 2006.

COMPANHIA ESTADUAL DE GERAÇÃO E TRANSMISSÃO DE ENERGIA ELÉTRICA. Plano de Uso e Ocupação do Solo no Entorno do Reservatório da UHE Passo Real. 2011. Disponível em: <http://www.ceee.com.br/ pportal/ceee/Component/Controller.aspx?CC=29417> . Acesso em 15 fev. 2017.

CORAZZA, Gentil. Fronteira Sul: traços da formação econômica. In: RADIN, José Carlos; VALENTINI, Delmir; ZARTH, Paulo. (Org.). História da Fronteira Sul. Porto Alegre: Ed. UFFS, 2015. p. 298-317.

DARÓS, Gildo. Conscientização de agricultores numa área de reforma agrária - Passo Real (RS). 1973. Dissertação (Mestrado em Economia Rural e Sociologia Rural) - Universidade Federal do Rio Grande do Sul, Porto Alegre, 1973. 
ECKERT, Córdula. O Master e as ocupações de terra no Rio Grande do Sul. In: FERNANDES, Bernardo Mançano; MEDEIROS, Leonilde Servolo de; PAULILO, Maria Ignez (Org.). Lutas camponesas contemporâneas: condições, dilemas e conquistas, v. 1: o campesinato como sujeito político nas décadas de 1950 a 1980. São Paulo: Editora Unesp, 2009. p. 71-92.

FERNANDES, Bernardo Mançano. A Formação do MST no Brasil. Petrópolis: Vozes, 2000.

GOHN, Maria da Gloria. História dos movimentos e lutas sociais: a construção da cidadania dos brasileiros. 7. ed. São Paulo: Loyola, 2012.

JASPER, James, M. Protesto: uma introdução aos movimentos sociais. Rio de Janeiro: Zahar, 2016.

IOKOI, Zilda Márcia Grícoli. As Lutas Camponesas no Rio Grande do Sul e a Formação do MST. Revista Brasileira de História, São Paulo, v. 11, n. 22, p. 49-70, mar./ago. 1991.

MCCARTHY, John D.; ZALD, Mayer N. Resource mobilization and social movements: a partial theory. The American Journal of Sociology, Chicago, v. 82, n. 6, p. 1212-1241, May 1977.

MARCON, Telmo. Acampamento Natalino: história da luta pela reforma agrária. Passo Fundo: Ediupf, 1997.

ROTHMAN, Franklin Daniel. A emergência do movimento dos atingidos pelas barragens da bacia do rio Uruguai (1979-1983). In: NAVARRO, Zander (Org.). Politica, protesto e cidadania no campo: as lutas sociais dos colonos e trabalhadores rurais no Rio Grande do Sul. Porto Alegre: Editora da Ufrgs, 1996. p. 106136.

SILVA, José Graziano da. O que é questão agrária. São Paulo: Brasiliense, 2007.

SNOW, David A.; BENFORD, Robert D. Master frames and cycles of protest. In: MORRIS, A.; MUELLER, C. M. (Org.). Frontiers in social movement theory. London: Yale University Press, 1992. p. 133-55.
TARROW, Sidney. O poder em movimento: movimentos sociais e confrontos políticos. Petrópolis: Vozes, 2009.

TEDESCO, João Carlos; MARCON, Telmo. As transformações na agricultura e as terras indígenas. In: MARCON, Telmo (Coord.). História e Cultura Kaingang no Sul do Brasil. Passo Fundo: UPF Editora, 1994. p. 162-199.

TEDESCO, João Carlos. O “Conflito de Nonoai": um marco na História das lutas pela terra no Rio Grande do Sul - 1978-1982. Sxculum - Revista de História, João Pessoa, n. 26, p. 241259, jan./jun. 2012.

TEDESCO, João Carlos; CARINI, Joel João. Conflitos agrários no norte gaúcho, 1960-1980: o Master, indígenas e camponeses. Porto Alegre: EST, 2007.

TILLY, Charles. From mobilization to revolution. Reading: Addison-Wesley, 1977.

VIEIRA, Flávia Braga. Dos proletariados unidos à globalização da esperança: um estudo sobre internacionalismos e a Via Campesina. São Paulo: Alameda, 2011. 